УДК 621.396, 621.3.049

\title{
ВОЛНОВОДНО-ЩЕЛЕВОЙ 24-КАНАЛЬНЫЙ ДЕЛИТЕЛЬ МОЩНОСТИ КИ-ДИАПАЗОНА С МАЛЫМИ ПОТЕРЯМИ
}

\author{
М. Ю. ОМЕЛЬЯНЕНКО, О. В. ТУРЕЕВА
}

\begin{abstract}
Аннотация. Предложен и разработан 24-канальный делитель мощности Ки-диапазона для активной фазированной антенной решетки. Делитель построен по древовидной схеме и имеет структуру $1 \times 3 \times 2 \times 2 \times 2$, а все его элементы выполнены на основе волноводно-щелевой линии. Благодаря этому вносимые дополнительные потери в изготовленном образце составили 1,8 дБ, что соответствует значению КПД $\approx 66 \%$. Измеренная развязка выходов делителя составила не менее 16 дБ для любой пары каналов при неравномерности деления мощности между каналами не более 0,3 дБ в рабочем диапазоне частот 9-14 ГГц.
\end{abstract}

Ключевые слова: ???

Разработка многоканальных делителей мощности с малыми вносимыми дополнительными потерями в коротковолновой части сантиметрового и миллиметровом диапазонах длин волн связана с разработкой многоэлементных активных фазированных решеток в этих диапазонах частот. В частности, для многоэлементных решеток, каждый из элементов которых содержит трансивер, делители мощности должны обеспечить равномерное распределение мощности гетеродинов преобразователей частоты и высокую развязку выходов. При этом собственные потери в них должны быть сведены к минимуму. Желательно также, чтобы конструкция делителя была планарной, что обеспечит повторяемость характеристик, исключит настройку и снизит его стоимость.

Делители мощности, реализующие перечисленные требования, можно условно разделить на две группы. К первой группе относятся делители мощности, представляющие собой бинарную древовидную структуру и реализуемые на базе каскадного соединения микрополосковых делителей мощности Уилкинсона или их модификаций [1]. Существенным недостатком такого построения является быстрый рост дополнительных потерь с увеличением каскадов деления, в результате чего КПД устройства уменьшается как $1 / L^{K}$, где $K=\log _{2} N$ - число каскадов деления, $L$ - потери на один каскад, $N$ - число выходов делителя.

Кроме того, при расчете ожидаемого значения КПД необходимо учитывать потери в межсекционных линиях связи, размеры которых для исключения взаимного влияния секций должны быть значительными [2].

При использовании в качестве подложки микрополосковой линии (МПЛ) современных полимерных материалов величину $L$ на частотах Ku-диапазона частот не удается снизить ниже уровня менее 1,2 дБ. Таким образом, уже 16-канальный делитель имеет дополнительные потери около 5 дБ и КПД $\approx 30 \%$. Эти цифры соответствуют полученным авторами экспериментальным данным, согласно которым 16-канальный микрополосковый делитель на материале Rogers RT5880 (толщина подложки 


\section{БИБЛИОГРАФИЧЕСКИЙ СПИСОК}

1. Burdin, F.; Podevin, F.; Ferrari, P. "Flexible and miniaturized power divider," Int. J. Microwave Wireless Technol., Vol. 8, No. 3, P. 547-557, 2016. DOI: 10.1017/ S1759078715000252.

2. Zhou, J.; Morris, K. A.; Lancaster, M. J. "General design of multiway multisection power dividers by interconnecting two-way dividers," IEEE Trans. Microwave Theory Tech., Vol. 55, No. 10, P. 2208-2215, 2007. DOI: $10.1109 /$ TMTT.2007.906541.

3. Fathy, A. E.; Lee, S.-W.; Kalokitis, D. “A simplified design approach for radial power combiners," IEEE Trans. Microwave Theory Tech., Vol. 54, No. 1, P. 247-255, 2006. DOI: 10.1109/TMTT.2005.860302.

4. Ghanadi, M. "A new compact broadband radial power combiner," Dissert. Doktor der Ingenieurwissenschaften Dr.-Ing. Elektrotechnik und Informatik der Technischen Universität Berlin, 2012. 102 p.

5. De Villiers, D. I. L.; Van Der Walt, P. W.; Meyer, P. "Design of a ten-way conical transmission line power combiner," IEEE Trans. Microwave Theory Tech., Vol. 
55, No. 2, P. 302-308, 2007. DOI: 10.1109/TMTT.2006. $\underline{890065}$.

6. Song, K.; Fan, Y.; Zhou, X. "Broadband radial waveguide power amplifier using a spatial power combining technique," IET Microwaves, Antennas Propag., Vol. 3, No. 8, P. 1179-1185, 2009. DOI: 10.1049/ietmap.2008.0299.

7. Li, L.; Wu, K. "Integrated planar spatial power combiner," IEEE Trans. Microwave Theory Tech., Vol.
54, No. 4, P. 1470-1476, 2006. DOI: 10.1109/TMTT. 2006.871360 .

8. Klopfenstein, R. W. "A transmission line taper of improved design," Proc. IRE, Vol. 44, No. 1, P. 31-35, 1956. DOI: $\underline{10.1109 / J R P R O C .1956 .274847 .}$

9. Ruxton, J.; Vahldieck, R. "A wideband finline power divider in a metallized plastic housing: design and performance," MTT-S Int. Microwave Symp. Dig., 9 May-11 Jun. 1987, Palo Alto, CA, USA. IEEE, 1987, P. 215-218. DOI: 10.1109/MWSYM.1987.1132366. 